Fecha de recepción: agosto 2014 Fecha de aceptación: octubre 2014 Versión final: marzo 2015

\section{Fase, la necesidad del encuentro}

Patricia Moreira *

Resumen: Este texto da cuenta de la relación arte, tecnología e investigación en los países latinoamericanos y cómo Fase se constituyó en un espacio de encuentro.

Palabras clave: arte - tecnología - investigación - curaduría

[Resúmenes en inglés y portugués en las páginas 40-41]

${ }^{(*)}$ Productora en artes visuales. Directora de Cine, especializada en producción. Directora de Fase. Docente de la Universidad de Palermo en la Facultad de Diseño y Comunicación.

Y entonces se establecerá el dialogo de las maquinas

Y lo informacional, remplazará, triunfante,

El cadáver vacío de la estructura divina;

Y luego funcionarán hasta el fin de los tiempos.

(Michel Houellebecq)

Fase se planteó desde sus comienzos en el año 2009 como un espacio de encuentro, crítica y exhibición de los trabajos que producían las intersecciones entre arte, ciencia y tecnología. Entendiendo a la cultura como un proceso dinámico, un sistema que se manifiesta en las acciones concretas de los hombres, el ser y estar en permanente transformación; el arte, la ciencia y la tecnología ejercen una función activa al ser recursos indispensables para esta función dinámica en la cual el hombre siempre buscará respuestas a históricas preguntas. Durante muchísimos años en la cultura occidental ambos sistemas, arte y ciencia, han intentado dar respuestas o generar nuevos interrogantes pero lo han hecho con diferentes métodos o sin ellos, utilizando la estética o el conocimiento, la evocación o la explicación, la emoción o la razón.

Partiendo de la conclusión presentada por Charles Pery Snow en su conferencia "Las dos culturas" dictada en la Universidad de Cambridge en el año 1959, se plantea la diferencia imperante entre humanistas y artistas por un lado y científicos por otro, indicando que se habían desarrollado lenguajes lo suficientemente diferentes para no comprenderse entre sí. Entonces Snow abría un debate, que más de sesenta años después continúa, cuando plantea "cerrar el abismo que separa nuestras culturas es una necesidad (...) Cuando esos dos sentidos se disgregan, ninguna sociedad es ya capaz de pensar con cordura". (2014) 
En el devenir histórico de la cultura occidental, hay múltiples antecedentes de encuentros posibles entre arte y ciencia con mejores y peores resultados tanto formales como informales.

En este marco, y sabiendo cada uno su especificidad de conocimiento, es imperiosa -hoy más que nunca- la necesidad de cerrar ese abismo del que habla Snow para encarar las nuevas problemáticas que nos plantea el universo transmediatico que creamos y por el que caminamos. (1987)

Para dar cuenta de este universo debemos sumar a la tecnología, considerada como aquel conjunto de herramientas que permiten modificar o adaptar el medio que habitamos mediante el uso de máquinas u artefactos. Es particularmente interesante la aclaración que hace Claudia Kozak cuando dice:

Es habitual sumar a la idea de tecnología la de contemporáneo, aunque esto no tenga razón necesaria sino de uso. Así enunciados como "nuevas tecnologías" o "tecnologías de punta" se aplican tanto en sentido restringido a dispositivos tecnológicos específicos como al conjunto de dispositivos (técnicas y tecnologías) que modelan el mundo contemporáneo. (2012)

Esta es la mirada sobre la tecnología que más se acerca a nuestro punto de interés por plantear su proximidad a la idea de arte contemporáneo.

Planteadas estas tres categorías y su necesidad de articulación en todos los órdenes: investigación, producción y gestión vale narrar el escenario desde el cual partió la creación de Fase. Buenos Aires, año 2009: ciudad de gran pluralidad cultural, activa, con instituciones educativas, laboratorios de investigación, colectivos artísticos independientes, investigando y produciendo trabajos que dan cuenta del cruce de arte, ciencia y tecnología con diversos e interesantes resultados. Estas interacciones que se daban en los ámbitos privados de cada espacio, lograban escasa articulación entre ellos. Entonces el desafío fue cómo crear un espacio para el encuentro y discusión de las problemáticas que transitábamos como sociedad en este nuevo modelo donde la tecnología ocupó un lugar relevante en la cotidianeidad de las personas. La propuesta fue crear un evento en el cual artistas, científicos, tecnólogos, teóricos, curadores, gestores culturales y productores pudieran compartir, debatir, generar nuevas redes de acción y conocimiento. Así nació Fase. La comunidad lo aceptó rápidamente, se apropió de él y lo hizo crecer a través del compromiso que cada uno aportó año tras año. De esta manera se llegó hasta aquí, luego de cinco ediciones consecutivas y a punto de dar comienzo a Fase 6.0.

En cada una de las ediciones se tomó un tema como propuesta disparadora para el desarrollo del pensamiento crítico y los trabajos expositivos ya sean en proceso $u$ acabados. Siempre, recordando desde la dirección y curaduría del encuentro, la necesidad de colaborar con el "cierre del abismo". Las temáticas abordadas cronológicamente fueron las siguientes: El estado de la Cuestión / Utopías-Distopías-Atopías / Zona de Prueba / Post-ecología: hacia una naturaleza y cultura sustentable / Metáforas de la supervivencia / Tecnologías: políticas y poéticas.

Los desafíos se renuevan, porque el mundo lo hace y la responsabilidad es mucha. En estos años se pudieron observar diferentes procesos creativos, multidisciplinarios, a veces gru- 
pales, otros individuales pero, nunca, sin la necesidad de un otro (espectador) que exige un compartir la experiencia artística. Hoy ese compartir puede ser virtual o presencial. La gran participación e influencia que tiene la tecnología en nuestras vidas ha generado, entre muchas otras cosas, nuevas formas de comunicación que a su vez generan nuevas problemáticas y preguntas sobre qué pasa en estos nuevos contextos con el territorio, las fronteras, las relaciones interpersonales, lo presencial y la privacidad. Todos los que forman parte de este ensamble están inmersos en un nuevo escenario compartiendo experiencias y haciendo que sus lenguajes puedan ser comprendidos y compartidos.

En Fase dieron cuenta de esta intersección diversas obras, como por ejemplo, "Generador de Consciencia I y II de la serie @Agua_Y_Aceite”, instalación robótica que trabaja con datos de la tasa de mortalidad de la Argentina de personas que mueren por falta de atención médica. Obra realizada en el año 2011 en el marco del mediaLab grupo de investigación perteneciente al Centro Cultural de España en Buenos Aires contó con la autoría de Daniel Álvarez Olmedo, Diego Diez y Guido Villar como creadores artísticos del proyecto y contaron con un equipo de colaboradores conformado por biólogos, bioquímicos y especialistas como Joaquín Fargas director del laboratorio Argentino de Bioarte de la Universidad Maimónides.

Otro ejemplo que nos vuelve a la premisa de este texto fue El Arca Obrera, presentada en Fase 4.0 por el Museo Taller Ferrowite conformado por Guillermo Beluzo, Roberto Orzali, Roberto Conte, Reynaldo Merlino, Angel Caputo y Nicolás Testoni. Una balsa diseñada y construida a partir de bidones en desuso que se botó en la ría de Bahía Blanca, Argentina. En este caso se preguntó qué reunió a un arquitecto con un marino mercante, a un artista plástico con un buzo táctico, al patrón de una draga con un videasta:

Quizá la posibilidad de que al cabo de la travesía, ya no sea posible distinguir con precisión quien es quien (...) Tal vez la pregunta implícita en el proceso de su construcción, exhibición y uso es qué tipo de lazos somos capaces de tramar en el disenso. Que nuevas escenas de la igualdad nos es dado proponer, entre lo propio y lo ajeno, cada vez que de mantenerse unidos depende mantenernos a flote.

En este sentido preguntarnos quien es quien nos lleva a volver a pensar la idea del retorno a la comunidad tan sacrificada en el siglo XX por el individualismo, asumiendo los nuevos desafíos que impone la era de la tecnología digital. Como dice Carlo Martinez Franco: "Si los problemas mundiales son demasiado grandes para que una mente pueda resolverlos fabriquemos entonces mentes conjuntas de mayor tamaño que alivien las preocupaciones de todos". (2010, p. 211)

Fase mira hacia el futuro y su pregunta continúa acerca de las políticas y poéticas de las tecnologías.

Como se ha mencionado anteriormente, Fase se constituye desde hace seis años como el único encuentro constante y se plantea nuevos desafíos en su gestión y contenido. Conformado por distintos secciones que se basaron en los conceptos de formación / exhibición / reflexión y extensión, el encuentro se detiene frente a los nuevos escenarios y para esto ha convocado a un equipo de investigación formado por teóricos, artistas, montajistas y 
productores quienes se encuentran trabajando en nuevos abordajes para las relaciones entre arte contemporáneo, ciencia y nuevas tecnologías.

Tecnologías: políticas y poéticas es el eje curatorial sobre el que se presentará Fase 6.0 donde se profundizará en la investigación de las poéticas de la generación actual. La construcción de una nueva mirada que no deja por fuera la búsqueda de sentido tanto político como poético. Ambos escasos de neutralidad, sabiendo que en cada una de nuestras decisiones cotidianas comprometemos a una cadena de acciones y personas. Esto nos exige ser reflexivos y consecuentes.

\section{Algunas consideraciones finales}

Este texto ha intentado dar cuenta de la necesidad de interacción entre el arte, la ciencia y la tecnología que generan nuevas prácticas contemporáneas. Nuevas simbologías se crean y enriquecen en este cruce. El dialogo ya está establecido, aún entrando en conflicto y aunque le cueste a cada una de sus partes la decodificación de lenguajes crípticos, la voluntad y necesidad son el germen del encuentro para seguir pensando al hombre inmerso en este mundo que construye y habita.

\section{Referencias Bibliográficas:}

Houellebecq, M. (2014). Non réconcilié. Anhologie personnelle 1991-2013. París: Ediciones Gallimard.

Kozak, C. (2012). Tecnopoéticas Argentinas. Archivo blando de arte y tecnología. Buenos Aires: Caja Negra Editora.

Martinez Franco, C. (2010). La Cultura Transversal. Colaboraciones entre arte ciencia y tecnología. Pasaje Cruzado. España. Universidad de Vigo. Equipo de Investigación SegúnPE1. Servicio de Publicaciones.

Snow Peirce, CH. (1987). Las dos culturas y un segundo enfoque. Madrid: Alianza Editorial.

\section{Notas:}

Catálogo de Fase 4.0 (2012) Museo Ferrowite. El Arca Obrera.

Summary: This article explains the relationship between art, technology and research in Latin American countries and how Fase became a meeting place.

Keywords: art - technology - research - conservatorship. 
Resumo: O texto relata a relação entre arte, tecnologia e pesquisa nos paises latino-americanos e como Fase se voltou um espaço de encontro.

Palavras chave: arte - tecnologia - pesquisa - curadoria. 